\title{
Awareness Penggunaan dan Pemanfaatan Public Cloud Storage di Indonesia
}

\author{
David Sundoro \\ Program Studi Sistem Informasi \\ Universitas Matana \\ david.sundoro@gmail.com
}

\begin{abstract}
Abstrak - Semakin besarnya tingkat urgensi dari data serta tingginya mobilitas pengguna internet pada masa sekarang menuntut dukungan dari tempat penyimpanan data atau storage. Teknologi informasi pada perkembangannya menawarkan layanan cloud storage yang bisa dimanfaatkan oleh pengguna internet sebagai tempat penyimpanan data yang fleksibel untuk diakses dari mana saja oleh pengguna, selama akses ke internet tersedia. Penelitian ini bertujuan untuk melihat tingkat awareness dari pengguna internet di Indonesia, didalam menggunakan dan memanfaatkan public cloud storage tidak berbayar (gratis) yang disediakan oleh beberapa penyedia jasa cloud storage.
\end{abstract}

Kata Kunci - Public Could Storage, internet, tingkat awareness

\section{PENDAHULUAN}

Meningkatnya mobilitas masyarakat pengguna teknologi informasi, juga meningkatkan kebutuhan atas tempat penyimpanan data yang relatif murah dan mudah untuk diakses. Mobilitas yang tinggi tersebut menuntut sifat ubiquity atau "ada di semua tempat", agar pengguna teknologi semakin mudah untuk menyimpan data.

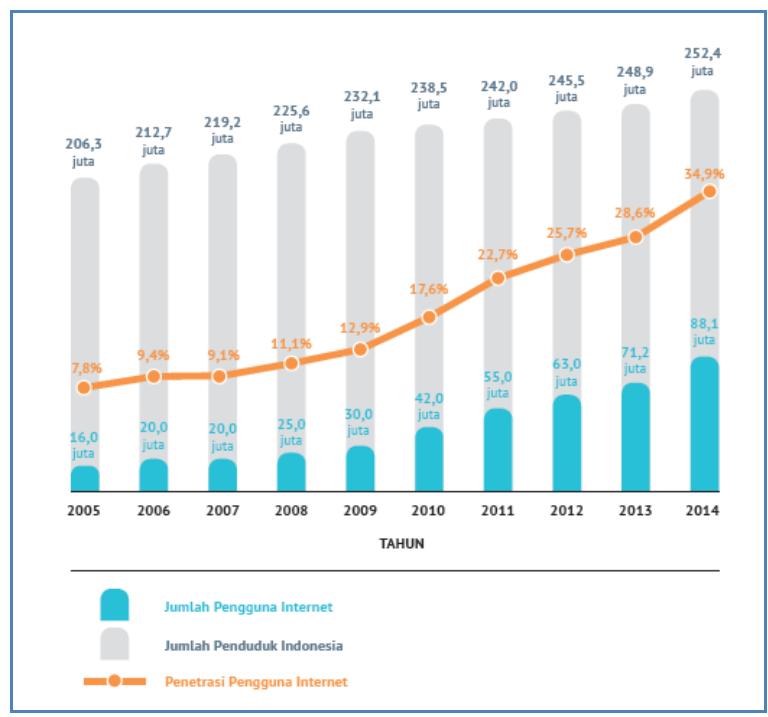

Gambar 1. Jumlah dan penetrasi pengguna internet di Indonesia

(Sumber : Survei APJII 2014 v3)
Makin besarnya jumlah pengguna internet di Indonesia, yang mencapai 88,1 juta pengguna (APJII, 2014), dengan tingkat penetrasi pengguna internet mencapai angka $34,9 \%$. Adanya kecenderungan peningkatan jumlah pengguna internet ini, idealnya juga akan meningkatkan jumlah penggunaan cloud storage.

Tujuan dari penelitian ini adalah untuk melihat tingkat kesadaran atau awareness pengguna Internet terhadap penggunaan dan pemanfaatan cloud storage di Indonesia, di dalam pekerjaan atau pun aktivitas sehari-hari.

\section{DEFINISI CLOUD STORAGE}

Cloud storage merupakan salah satu bagian yang tidak bisa dipisahkan dari cloud computing, yang dipergunakan dalam menyimpan data, dengan memanfaatkan server pihak ketiga sebagai penyedia jasa (Wu, 2010). Pada saat penyimpanan data, pengguna melihat sebuah server secara virtual, di mana tempat atau lokasi dari server tersebut tidak benar-benar diketahui. Meski demikian, pengguna melihat keberadaan storage tersebut secara statis pada perangkat komputernya.

Cloud storage memiliki keuntungan yang bisa dinikmati baik dari segi finansial maupun kenyamanan. Keuntungan finansial bisa dirasakan karena sumber daya secara virtual yang dipergunakan lebih murah jika dibandingkan dengan sumber daya yang harus dibeli secara fisik. Sementara dari sisi kenyamanan, data yang dimiliki oleh pengguna cloud storage terlindungi dari kemungkinan hilang akibat kerusakan perangkat keras. Ini dikarenakan, cloud storage melakukan proses back-up ke perangkat keras yang lain, yang menyokong atau mendukung sistem tersebut $(\mathrm{Wu}$, 2010).

\section{METODOLOGI PENELITIAN}

Penelitian ini dilakukan terhadap 79 orang responden pengguna internet, yang terdiri dari 57 orang pria dan 22 orang wanita, dengan rentang usia antara 17 hingga 50 tahun, Dengan bidang profesi atau pekerjaan yang bervariasi.

Angket dalam penelitian ini disebarkan dan diisi secara elektronik, sehingga bisa disimpulkan bahwa responden yang 
terlibat adalah pengguna perangkat teknologi informasi dan layanan internet, dengan latar belakang profesi yang beragam.
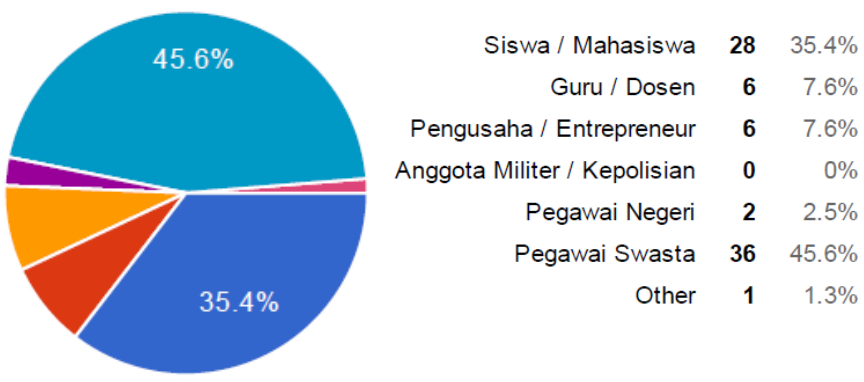

Gambar 2. Demografi responden yang ikut dalam penelitian ini

\section{PEMBAHASAN}

Dari penelitian singkat ini, diperoleh data bahwa dari 79 orang responden yang mengisi kuesioner, $84,8 \% \quad$ (67 responden) diantaranya adalah pengguna cloud storage, sementara $15,2 \%$ (12 responden) sisanya bukan merupakan pengguna.

\subsection{Responden yang memanfaatkan Cloud Storage}

Dari 67 responden yang menjadi pengguna cloud storage, diperoleh data bahwa sebagian besar dari mereka mempergunakan 3 aplikasi cloud storage yang cukup popular, yakni :
1. DropBox
2. Google Drive
3. Microsoft One Drive
sebanyak $83,6 \%$
sebanyak $74,6 \%$
sebanyak $29,9 \%$
4. Cloud storage lain sebanyak $13,4 \%$

Pengguna baru dari layanan cloud storage ini pun menunjukkan peningkatan. Dari 67 responden pengguna layanan ini, 25,3\% diantaranya adalah pengguna yang baru mempergunakan cloud storage selama rentang $0-12$ bulan.

Meskipun $84,8 \%$ responen adalah pengguna, sebagian responen merasakan bahwa manfaat yang diberikan masih tidak memenuhi harapan mereka. Terdapat $16,4 \%$ responden yang menyatakan tidak merasakan manfaat yang besar dari penggunaan cloud storage. Dan hanya 46 responden yang benar-benar merasakan manfaat dari layanan ini.

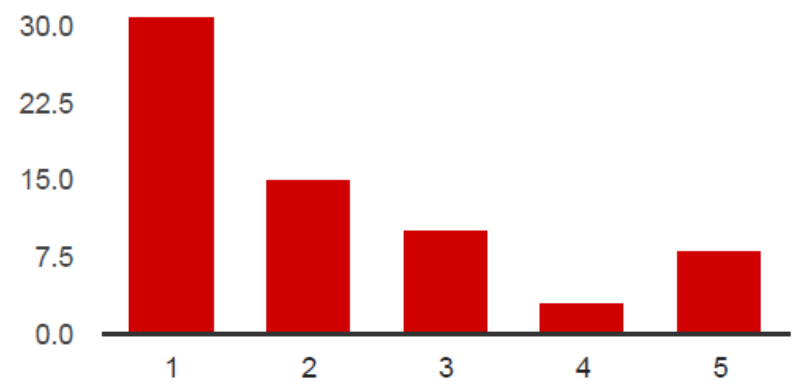

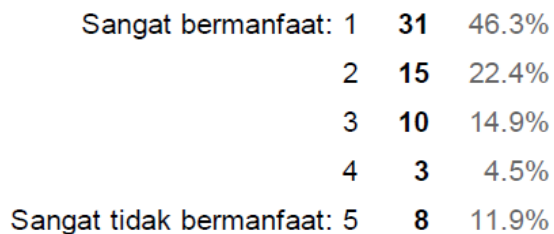

Gambar 3. Tingkat manfaat cloud storage menurut responden

Sementara, dari 67 responden yang menggunakan, terdapat 59,7\% (40 orang) yang merasa yakin dengan keamanan layanan yang diberikan oleh penyedia jasa cloud storage. Dan hanya $16,4 \%$ (11 orang) pengguna yang merasa tidak yakin dengan keamanan data mereka di cloud storage.

Dalam penelitian ini, keamanan merupakan hal yang paling penting menurut para responden. Terdapat 35,8\% (24 orang) responden yang menilai keamanan data menempati prioritas yang sangat penting, disusul dengan 20,9\% (14 orang) responden yang menyatakan cukup penting. Sementara kecepatan akses data menempati posisi kedua di mana 28,4\% (19 orang) responden menilai kecepatan adalah sangat penting, disusul dengan $23,9 \%$ (16 orang) responden yang menilai bahwa kecepatan cukup penting.

Salah satu fitur yang ditawarkan oleh cloud storage adalah sinkronisasi secara otomatis bagi penggunanya yang memiliki tingkat mobilitas tinggi, dan menggunakan beberapa perangkat yang berbeda. Fitur ini bertujuan agar setiap perubahan data yang dilakukan di salah satu perangkat akan dengan otomatis memperbarui data yang juga disimpan di perangkat yang lain, pada saat perangkat tersebut aktif dan terhubung dengan layanan internet. Dalam penelitian ini, dari 67 orang responden pengguna cloud storage, terdapat $74,6 \%$ (50 orang) pengguna saja yang memanfaatkan fitur sinkronisasi ini.

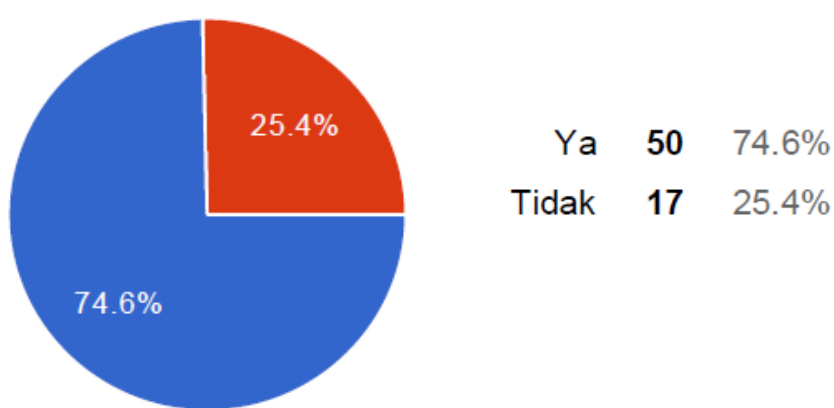

Gambar 4. Pemanfaatan cloud storage sebagai media sinkronisasi data

Namun, meski menggunakan cloud storage, tidak berarti back-up data tidak dilakukan oleh para responden. Terdapat $73,1 \%$ (49 orang) responden yang juga mempergunakan External Hard Drive (USB), disusul Thumb Drive (USB 
Flash Drive) sebanyak 71,6\% (48 orang) responden, sebagai media penyimpanan data selain cloud storage.

\subsection{Responden yang tidak menggunakan Cloud Storage}

Sementara itu dari 15,2\% (12 orang) dari keseluruhan responden yang tidak mempergunakan cloud storage, terdapat $33,3 \%$ (4 orang) responden yang tidak mengetahui sama sekali tentang layanan ini. Sementara 33,3\% (4 orang) lagi yang menyatakan bahwa penyebab mereka tidak menggunakan layanan ini dikarenakan biaya akses internet yang mahal.

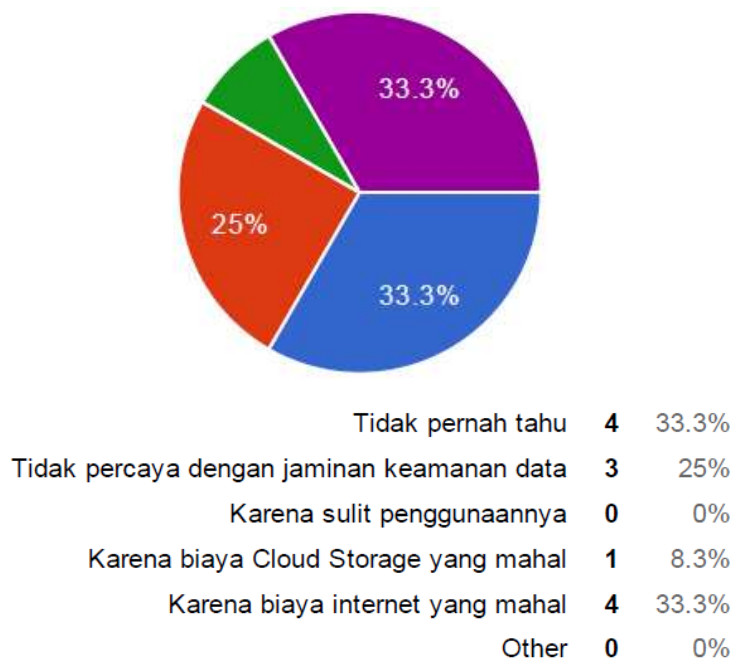

Gambar 5. Alasan tidak menggunakan cloud storage

Dari 12 orang responden yang belum menggunakan cloud storage, terdapat $83,3 \%$ (10 orang) responden yang menyatakan berencana untuk menggunakan layanan ini di masa mendatang, dan hanya 2 (dua) orang yang tidak memiliki rencana untuk mempergunakannya. 3 (tiga) orang responden yang menyatakan tidak percaya terhadap jaminan keamanan data yang ditawarkan atau dijamin oleh penyedia layanan cloud storage.

\section{KESIMPULAN}

Dari 79 responden yang terlibat dalam penelitian, terlihat bahwa cukup banyak pengguna layanan cloud storage, seiring dengan meningkatnya pengguna internet di Indonesia. Adanya pertambahan pengguna yang baru memanfaatkan dalam setahun terakhir dan rencana dari pengguna internet yang belum untuk memanfaatkan cloud storage, menunjukkan kecenderungan akan makin meningkatnya kebutuhan layanan ini. Demikian juga dengan awareness dari pengguna layanan ini, terhadap pentingnya keamanan dan kecepatan akses internet, secara khusus untuk layanan cloud storage, menunjukkan adanya peningkatan.
Secara eksplisit, masih terdapat terdapat hambatan dalam pemanfaatan teknologi ini yang lebih disebabkan karena keraguan pengguna atas jaminan keamanan, serta masih mahalnya layanan internet di Indonesia. Namun dalam penelitian ini juga terlihat bahwa ada kecenderungan peningkatan pengguna cloud storage di masa mendatang seiring dengan berkembang teknologi dan kebutuhan penyimpanan data dari pengguna teknologi informasi.

\section{PELUANG RISET DI MASA MENDATANG}

Penelitian ini hanya melihat tingkat awareness dari pengguna internet dalam memanfaatkan layanan cloud storage. Di masa mendatang, penelitian dapat lebih difokuskan pada implementasi penggunaan cloud storage, dalam berbagai industri yang bisa ditinjau dari segi biaya manfaat dan sudut pandang lainnya. Juga dapat ditinjau tingkat penggunaan cloud storage bagi pengguna yang melakukan akses dengan menggunakan mobile device seperti tablet atau smartphone.

Dari sisi teknis, bisa diteliti mengenai kesiapan infrastruktur dari layanan telekomunikasi dalam satu perusahaan yang dibutuhkan untuk mendukung pemanfaatan teknologi cloud storage ini.

\section{REFERENSI}

[1] Asosiasi Penyelenggara Jasa Internet Indonesia, 2014. Profil Pengguna Internet Indonesia 2014, Pusat Kajian Komunikasi Universitas Indonesia.

[2] Ian Foster, Yong Zhao, Ioan Raichu, and Shiyon Lu, 2008. Cloud Computing and Grid Computing 360Degree Compared.

[3] Iulia Ion, Niharika Sachdeva, Ponnurangam Kumaraguru, and Srdjan Capkun, 2011. Home is Safer than The Cloud! Privacy Concerns for Consumer Cloud Storage, Symposium on Useable Privacy and Security (SOUPS) 2011.

[4] Ricardo Neisse, Dominik Holling and Alexander Pretschner, 2011. Implementing Trust in Cloud Infrastructure.

[5] Christian Cachin, Idit Keidar, and Alexander Shraer, 2009. Trusting the Cloud.

David Sundoro adalah seorang staf pengajar pada Program Studi Sistem Informasi di Universitas Matana, Tangerang. Bidang riset yang diminati adalah Manajemen Proyek Teknologi Informasi, Sistem Informasi Manajemen, Jaringan Komputer, dan Intelijen Bisnis, Saat ini tercatat sebagai mahasiswa Program Doktoral Bidang Manajemen Sistem Informasi di Universitas Bina Nusantara, Jakarta 